\title{
Bio-Inspired Synthesis of a Silicate/PMMA Composite
}

\author{
Kyung Mok Nam*****, Yoon Joo Lee*, Woo Teck Kwon*, Soo Ryong Kim*, Dong-Geun Shin*, \\ Hyung Mi Lim*** Hyungsun Kim****, and Younghee Kim*** \\ *Energy Efficient Material Team, Korea Institute of Ceramic Engineering and Technology, Seoul 153-801, Korea \\ **Eco Composite Materials Team, Korea Institute of Ceramic Engineering and Technology, Seoul 153-801, Korea \\ *** School of Materials Engineering, Inha University, Incheon 402-751, Korea
}

(Received September 30, 2013; Revised January 3, 2014; Accepted January 5, 2014)

\begin{abstract}
Abalone shell is composed of $95 \mathrm{wt} \% \mathrm{CaCO}_{3}$ platelets and $5 \mathrm{wt} \%$ of a protein-rich organic matrix which acts as an adhesive layer, connecting aragonite tablets, thus maintaining the structural integrity of the composite. By mimicking abalone shell, we prepared a silicate plate/polymer nanocomposite by infiltrating PMMA between silicate layers and warm-pressing them at $200^{\circ} \mathrm{C}$ for $1 \mathrm{~h}$ under 15 tons to make organic-inorganic composite materials. To examine the organic-inorganic composite materials after the warm-pressing procedure, the composite sample was analyzed with FE-SEM and TG. The bending strengths and densities of the composites prepared by a silicate plate and PMMA after the warm-pressing process were $\sim 140 \mathrm{MPa}$ and 1.5 , respectively.
\end{abstract}

Key words : Bio-inspired, Composite, Abalone shell, Silicate, PMMA, Energy efficiency

\section{Introduction}

$\mathbf{N}$ atural materials such as abalone shell and nacre show outstanding mechanical properties due to their hierarchical structure at the nano, micro and meso levels. If we use the bio-inspired technology of an abalone shell nanocomposite in the ocean, energy-efficient research can be conducted on the mass production of higher strength, higher elasticity, and extremely lightweight advanced nanocomposite materials. Abalone shell is a biogenic composite consisting of alternating layers of mineral tablets separated by thin layers of a bio macromolecular matrix. Abalone shell is composed of $\sim 95 \mathrm{wt} \% \mathrm{CaCO}_{3}$ platelets, which have dimensions of $\sim 5-20 \mu \mathrm{m}$ in length and $\sim 0.5-1.0 \mu \mathrm{m}$ in thickness. The remaining $\sim 5 \mathrm{wt} \%$ of abalone shell is composed of a protein-rich organic matrix $\sim 30-50 \mathrm{~nm}$ in thickness which acts as an adhesive layer connecting aragonite tablets, thus maintaining the structural integrity of the composite. The sliding of contiguous $\mathrm{CaCO}_{3}$ platelets is made more difficult by the nano-asperities observed on the surfaces and by the need to rupture the connection bridges between the platelets, which increase the friction between them.

Podsiadlo et al. used a layer-by-layer (LBL) assembly technique to prepare a bio-inspired nanocomposite using Na-montmorillonite clay and polydiallyldimethylammonium chloride. The tensile strength and Young's modulus of

${ }^{\dagger}$ Corresponding author : Younghee Kim

E-mail : yhkokim@kicet.re.kr

Tel : +82-2-3282-2472 Fax : +82-2-3282-2430 the nanocomposite derived from the LBL method were approximately $100 \mathrm{MPa}$ and $11 \mathrm{GPa}$, respectively. ${ }^{1)}$

Recently, Erb et al. produced synthetic composites with a tuned three-dimensional orientation using micrometersized reinforcing particles coated with minimal concentrations of superparamagnetic nanoparticles with controlled ultralow magnetic fields. ${ }^{2}$

Various studies of the nanostructured materials in abalone shell have been carried out. However, efforts to imitate abalone shell remains at the level of forming plastic films. ${ }^{3-15)}$ Biological research on bio-inspired technologies continues, and certain mechanical structures can be reproduced in the laboratory. In this study, to make high-strength, lightweight ceramic composite materials using bio-inspired technology, a porous green body was prepared with a silicate platelet. PMMA was infiltrated into the porous green body, which was then warm-pressed to eliminate the pores present in the composite. The microstructure of the composite was observed with FE-SEM, and the mechanical and thermal properties were measured.

\section{Experimental Procedures}

\subsection{Preparation of the silicate plate}

Layered silicate, i.e., Na-ilerite, was used as a starting material. It was synthesized hydrothermally at $100^{\circ} \mathrm{C}$ for 2 weeks from a suspension of Ludox-HS 40 and a $\mathrm{NaOH}$ solution with the following molar ratio: $\mathrm{SiO}_{2}: \mathrm{NaOH}: \mathrm{H}_{2} \mathrm{O}$ $=1: 0.5: 7$. The chemical composition of the sample was $\mathrm{Na}_{2} \mathrm{Si}_{8} \mathrm{O}_{17}$, as determined by an atomic absorption spectrometer. 


\subsection{Preparation of silicate/PMMA composite}

Methyl methacrylate (MMA) monomer (99\%, Aldrich) and benzylperoxide (99\%, Aldrich), which was used as a catalyst for polymerizing the MMA, were used to formulate the bioinspired organic-inorganic composites. $10 \mathrm{~g}$ of silicate plate material was mixed with $0.5 \mathrm{~g}$ of phenolic resin as a binder to make silicate green bodies. The green bodies were prepared using a uniaxial pressing with a one-ton press, and a post-treatment step was done at $120^{\circ} \mathrm{C}$ to promote the hardness of the silicate green body. The silicate green body was then transferred into the MMA/benzylperoxide solution and boiled for 10min to infiltrate the MMA, after which it was cured at $80^{\circ} \mathrm{C}$ for $1 \mathrm{~h}$. The subsequent warm-pressing process was done using a uniaxial pressing with a 15 -ton press at $100^{\circ} \mathrm{C}$ and $200^{\circ} \mathrm{C}$ with a constant heating rate of $10^{\circ} \mathrm{C} /$ $\min$.

The microstructure of the prepared silicate/PMMA composite was characterized by TG (TGA 4000, Perkin Elmer) and scanning electron microscopy (JSM-6700F, JEOL). The bending strength of the silicate/PMMA was measured using an Instron 5848 tester. The bulk density was measured by gravimetry using the Archimedes principle. To characterize the combustion properties, the heat release capacity, total heat release and heat release rate were measured using a micro-calorimeter (Fire Testing Technology) in the range of $75-700^{\circ} \mathrm{C}$ under a mixture gas of nitrogen $(80 \mathrm{cc} / \mathrm{min})$ and oxygen $(20 \mathrm{cc} / \mathrm{min})$.

\section{Results and Discussion}

Layered silicates, such as kanemite $\left(\mathrm{NaHSi}_{2} \mathrm{O}_{5} \cdot 3 \mathrm{H}_{2} \mathrm{O}\right)$, magadiite $\left(\mathrm{NaSi}_{7} \mathrm{O}_{13}(\mathrm{OH})_{3} \cdot 4\left(\mathrm{H}_{2} \mathrm{O}\right)\right)$, kenyaite $\left(\mathrm{Na}_{2} \mathrm{Si}_{22} \mathrm{O}_{41}(\mathrm{OH})_{8}\right.$. $\left.6\left(\mathrm{H}_{2} \mathrm{O}\right)\right)$, makatite $\left(\mathrm{Na}_{2} \mathrm{Si}_{4} \mathrm{O}_{8} \cdot 4 \mathrm{H}_{2} \mathrm{O}\right)$ and ilerite $\left(\mathrm{Na}_{2} \mathrm{Si}_{8} \mathrm{O}_{17}\right.$ $\mathrm{xH}_{2} \mathrm{O}$ ), are composed of only tetrahedral silicate sheets, and each of the silicate sheets terminates with a hydroxyl group (Fig. 1). Consequently, layered silicates with a structure similar to that of clay possess abundant hydroxyl groups and have great potential as starting materials for an organic-inorganic hybrid nanocomposite.

Silicate platelets $3-5 \mu \mathrm{m}$ in length and $\sim 100 \mathrm{~nm}$ thick were used for the preparation of the green bodies into which the methyl methacrylate (MMA) monomer was to be infiltrated. Fig. 2 shows a SEM photograph of the silicate platelets used as the starting materials. Fig. 3 displays the TG data of the silicate/PMMA composites, showing that the weight loss of the two samples is due to the decomposition of the PMMA. The initiating decomposition temperatures of the silicate/PMMA composites are about $300^{\circ} \mathrm{C}$. However, above $400^{\circ} \mathrm{C}, 70 \%$ of the warm-pressed composite sample and $80 \%$ of the composite sample only infiltrated with PMMA remain. This suggests that the silicate/PMMA composites are composed of $70-80 \%$ silicate platelets, which is similar to a biogenic composite such as abalone shell.

The silicate/PMMA composites were prepared in two steps. First the infiltration-only sample was prepared using a hand press, and a post-treatment step was done at $120^{\circ} \mathrm{C}$
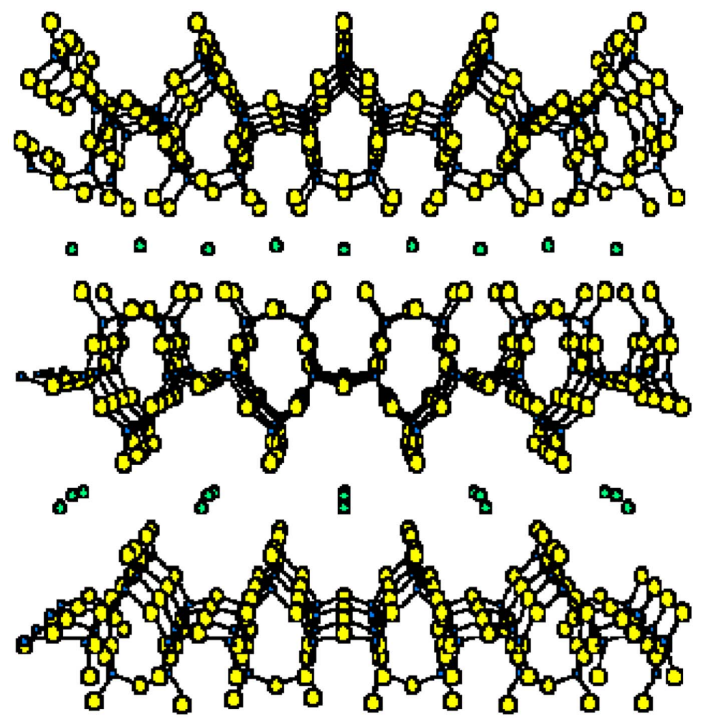

Fig. 1. Structure of layered Silicate.

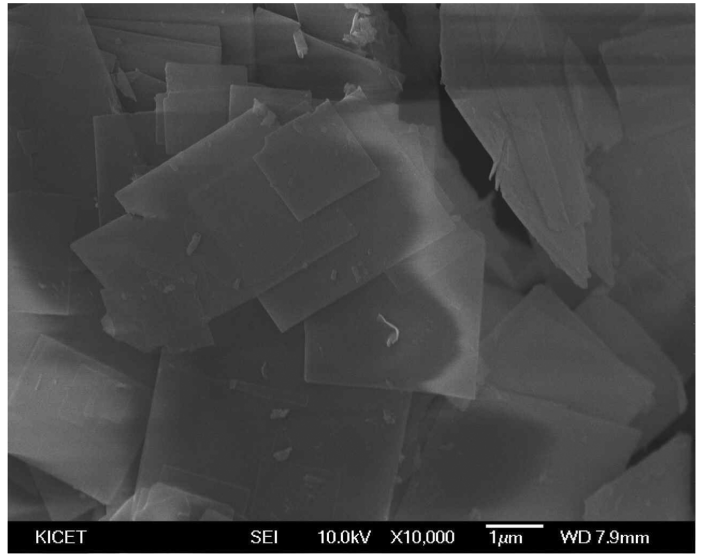

Fig. 2. SEM image of layered Silicate.

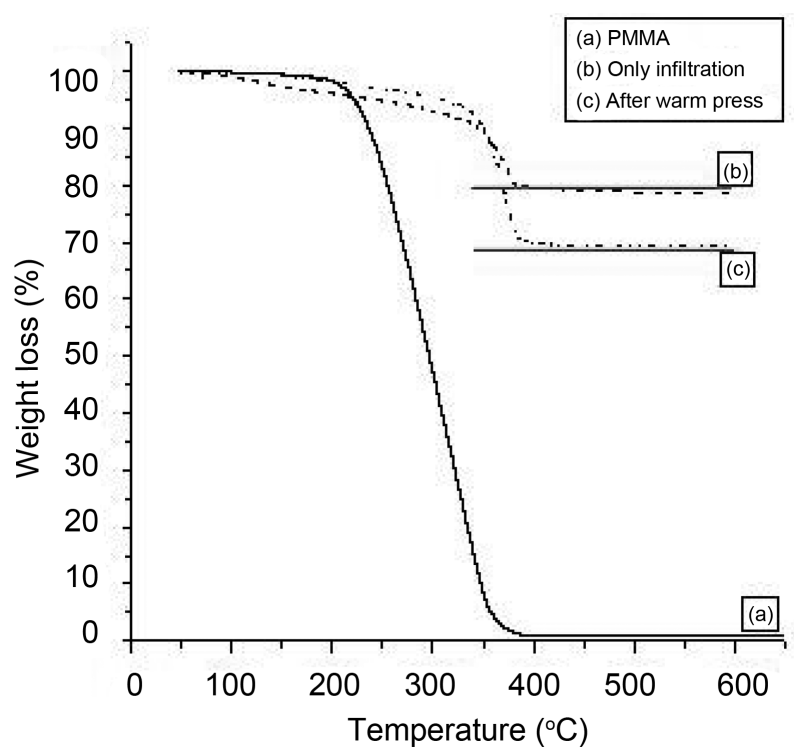

Fig. 3. TG analysis data of silicate/PMMA composites and PMMA. 


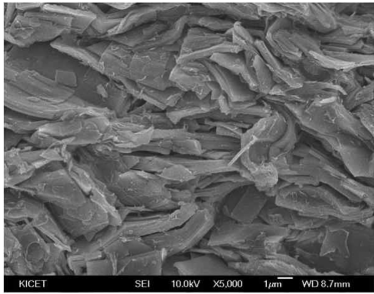

(a)

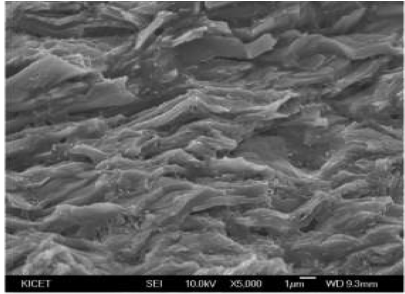

(b)
Fig. 4. SEM images of silicate/PMMA composites (a) only infiltration and (b) after warm press.

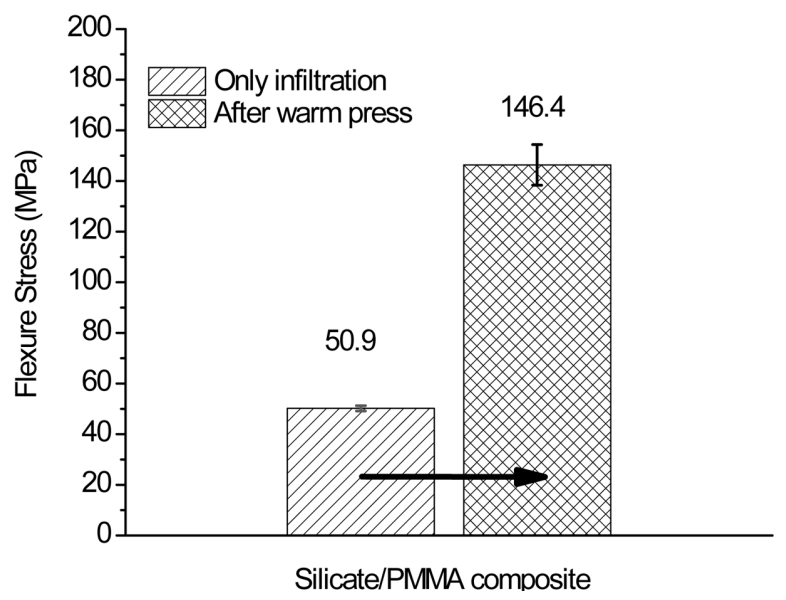

Fig. 5. Bending strength of silicate/PMMA composites.

to promote the hardness of the silicate green body. The silicate green body was then transferred to the MMA and benzylperoxide solution and boiled to infiltrate the MMA, after which it was cured. A second sample was prepared to improve the mechanical properties, and the subsequent warm-pressing process was carried out using a hand press with 15 tons of pressure at $100^{\circ} \mathrm{C}$ and $200^{\circ} \mathrm{C}$. After the second step, the composites were dense and the silicate platelets were aligned with a better shape.

To confirm that the silicate platelets were properly dispersed in the PMMA matrix, SEM images were observed of the fracture surface of the silicate/PMMA composites. Fig. 4(a) shows SEM micrographs of the fracture surface of a silicate/PMMA composite after the first step, in this case the infiltration-only sample. As shown in the image, the sample contains many pores. This is due to the poor infiltration of MMA into the silicate green body matrix. The pores in the silicate/PMMA composite reduce the mechanical properties. To remove these pores from the silicate/PMMA

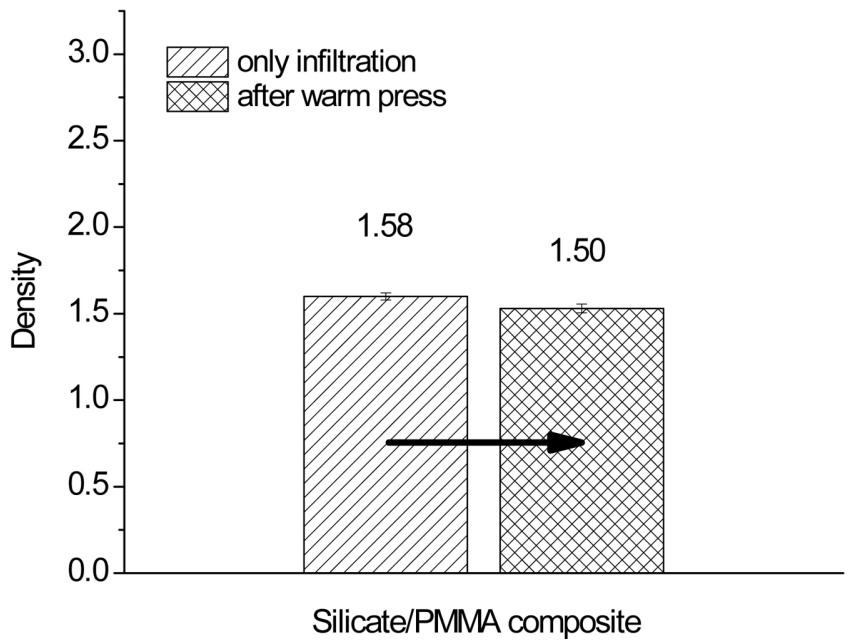

Fig. 6. Densities of silicate/PMMA composites.

composite, a second step involving a warm-pressing process was applied to the sample. After the warm-pressing step, the fracture surface of the silicate/PMMA composite became denser than it was before the treatment (Fig. 4(b)).

Three-point bending tests were performed in general accordance with ASTM standards to measure the mechanical properties. Fig. 5 shows the variation of the bending strength of the silicate/PMMA composite, showing two different samples. It is clear from this figure that the bending strength of the silicate/PMMA composite increases after the warm-pressing treatment. For the infiltrated-only sample, the bending strength is about $50 \mathrm{MPa}$. However, after the warm-pressing treatment, the bending strength of the silicate/PMMA composite reaches $146 \mathrm{MPa}$ maximum, as this composite is dense and the silicate platelets are aligned with a better shape after the warm-pressing step.

Figure 6 shows that the densities of the prepared silicate/ PMMA composite range from 1.50 to 1.58; these values are lower than the inherent density of silicate.

To characterize the combustion properties, the heat release capacity, the total heat release and the heat release rate were measured using a micro-calorimeter in the range of $75-700^{\circ} \mathrm{C}$ under a mixture gas of nitrogen and oxygen. The heat release (HR) capacity of the silicate/PMMA composite is reduced to $\sim 60 \mathrm{~J} / \mathrm{g} \cdot \mathrm{K}$, whereas the heat release (HR) capacity of PMMA itself is $\sim 250 \mathrm{~J} / \mathrm{g} \cdot \mathrm{K}$. Also, the total heat release (HR) of the silicate/PMMA composite is $\sim 5 \mathrm{~kJ} / \mathrm{g}$, which is lower than that of PMMA (Table 1). The micro-calorimeter measurements confirm that the silicate/PMMA

Table 1. HRR Data of PMMA and Layered Silicate/PMMA Composite

\begin{tabular}{cccccc}
\hline Sample & & Peak HRR $(\mathrm{W} / \mathrm{g})$ & Temp. $\left({ }^{\circ} \mathrm{C}\right)$ & Total HR $(\mathrm{kJ} / \mathrm{g})$ & HR Capacity $(\mathrm{J} / \mathrm{g} \cdot \mathrm{K})$ \\
\hline \multirow{2}{*}{ PMMA } & 1 & 246.9 & 388.8 & 22.7 & 243 \\
& 2 & 272.6 & 388.5 & 22.7 & 267 \\
\hline \multirow{2}{*}{ Silicate/PMMA Composite } & 1 & 86.6 & 402 & 6.0 & 80 \\
& 2 & 67.0 & 407 & 3.1 & 61 \\
& 3 & 46.4 & 399 & 3.9 & 40 \\
\hline
\end{tabular}


composite has lower flammability than the PMMA polymer.

\section{Conclusion}

By mimicking nacre, we prepared a silicate platelet/polymer nanocomposite via the infiltration of PMMA between silicate layers and warm-pressed them at $200^{\circ} \mathrm{C}$ for $1 \mathrm{~h}$ under 15 tons to make organic-inorganic composite materials. In order to examine the organic-inorganic composite materials after the warm-pressing process, the composite sample was analyzed with FE-SEM and TG. The bending strengths and densities of the composites prepared with the silicate platelets and PMMA after the warm-pressing process were $\sim 150 \mathrm{MPa}$ and 1.5 , respectively. This nanotechnology can be applied to energy-efficient buildings as well as to lightweight and elastic automobile body frames. The feasibility of this environmentally friendly technology can be evaluated through research that studies energy and the environment to reduce $\mathrm{CO}_{2}$ gas emissions.

\section{Acknowledgment}

This research was supported by the Pioneer Research Center Program through the National Research Foundation of Korea funded by the Ministry of Education, Science, and Technology (Grant No. 2010-0019468).

\section{REFERENCES}

1. P. Podsiadlo, Z. Liu, D. Paterson, P. B. Messersmith, and N. A. Kotov, "Fusion of Seashell Nacre and Marine Bioadhesive Analogs: High-Strength Nanocomposite by Layerby-Layer Assembly of Clay and L-3,4-Dihydroxyphenylalanine Polymer," Adv. Mater., 19 [7] 949-55 (2007).

2. R. M. Erb, R. Libanori, N. Rothfuchs, and A. R. Studart, "Composites Reinforced in Three Dimensions by Using Low Magnetic Fields," Science, 335 [6065] 199-204 (2012).

3. A. M. Belcher, X. H. Wu, R. J. Christensen, P. K. Hansma, G. D. Stucky, and D. E. Morse, "Control of Crystal Phase Switching and Orientation by Soluble Mollusc-shell Proteins," Nature, 381 56-58 (1996).

4. M. E. Launey, E. Munch, D. H. Alsem, H. B. Barth, E.
Saiz, A. P. Tomsia, and R.O. Ritchie, "Designing Highly Toughened Hybrid Composites Through Nature," Acta Mater., 57 [10] 2919-32 (2009).

5. E. Munch, M. E. Launey, D. H. Alsem, E. Saiz, A. P. Tomsia, and R. O. Ritchie, "Tough, Bio-Inspired Hybrid Materials," Science, 322 [5907] 1516-20 (2008).

6. L. J. Bonderer, A. R. Studart, and L. J. Gauckler, "Bioinspired Design and Assembly of Platelet Reinforced Polymer Films," Science, 319 [5866] 1069-73 (2008).

7. A. Chandra, L. S. Turng, K. Li, and H. X. Huang, "Fracture Behavior and Optical Properties of Melt Compounded Semitransparent Polycarbonate(PC)/Alumina Nanocomposites," Composites, Part A, 42 [12] 1903-09 (2011).

8. S. Zhao, L. S. Schadler, R. Duncan, H. Hillborg, and T. Auletta, "Mechanisms Leading to Improved Mechanical Performance in Nanoscale Alumina Filled Epoxy," Compos. Sci. Technol., 68 [14] 2965-75 (2008).

9. H. Liu, H. Ye, T. Lin, and T. Zhou, "Synthesis and Characterization of PMMA $/ \mathrm{Al}_{2} \mathrm{O}_{3}$ Composite Particles by in Situ Emulsion Polymerization," Particuology, 6 [3] 207-13 (2008).

10. X. Li, W. C. Chang, Y. J. Chao, R. Wang, and M. Chang "Nanoscale Structural and Mechanical Charaterization of a Natural Nanocomposite Material:the Shell of Red Abalone," Nano Lett., 4 [4] 613-17 (2004).

11. D. Kumar, K. Shukla, S. V. Kasisomayajula, and V. Parameswaran, "Epoxy Composites using Functionalized Alumina Platelets as Reinforcements," Compos. Sci. Technol., 68 [14] 3055-63 (2008).

12. F. Bennadji-Gridi, A. Smith, and J.-P. Bonnet, "Montmorillonite Based Artificial Nacre Prepared Via Drying Process," Mater. Sci. Eng. B, 130 [1-3] 132-36 (2006).

13. Y. L. Liu, C.Y. Hsu, and K. Y. Hsu, "Poly(methylmethacrylate)-silica Nanocomposites Films from Surface-functionalized Silica Nanoparticles," Polymer, 46 [6] 1851-56 (2005).

14. B. J. Ash, D. F. Rogers, C. J. Wiegand, L. S. Schalder, R. W. Siegel, B. C. Benicewicz, and T. Apple, "Mechanical Properties of $\mathrm{Al}_{2} \mathrm{O}_{3}$ /Polymethylmethacrylate Nanocomposites," Polym. Composite., 23 [6] 1014-25 (2002).

15. K. M. Nam, Y. J. Lee, W. T. Kwon, S. R. Kim, H. M. Lim, H. S. Kim, and Y. H. Kim, "Preparation of $\mathrm{Al}_{2} \mathrm{O}_{3}$ Platelet/ PMMA Composite and Its Mechanical/Therml Characterization," J. Kor. Ceram. Soc., 49 [5] 438-41 (2012). 